\title{
KNOWLEDGE OF MEDICAL PROFESSIONALS TOWARDS DENGUE DIAGNOSTICS
}

Saranya Selvanayaki Kamaraj1, Rubini Manimanna Sankarlal2, Ismail Mohamed³, Uma Alagappan4, Thirumalai Kolundu Subramaniam Ponniah ${ }^{5}$, Vazhavandal Ganesan ${ }^{6}$

${ }^{1}$ CRRI, Chennai Medical College Hospital and Research Centre, Irungalur, Trichy. ${ }^{2}$ CRRI, Chennai Medical College Hospital and Research Centre, Irungalur, Trichy. ${ }^{3}$ Research Co-ordinator, Chennai Medical College Hospital and Research Centre, Irungalur, Trichy. ${ }^{4}$ Professor, Department of Microbiology, Chennai Medical College Hospital and Research Centre, Irungalur, Trichy.

5 Professor, Department of Medicine, Chennai Medical College Hospital and Research Centre, Irungalur, Trichy. ${ }^{6}$ Associate Professor, Department of Microbiology, Chennai Medical College Hospital and Research Centre, Irungalur, Trichy.

\section{ABSTRACT}

Dengue is a major public health problem throughout the world. It is a rapidly spreading mosquito-borne viral disease with high rate of morbidity and mortality. Dengue can be reduced by implementing early case detection, reorienting health services, improving outbreak prediction and detection through coordinated epidemic and appropriate vector management. Various diagnostic techniques like ELISA, Rapid tests, etc. are very useful in diagnosis of dengue. Diagnosis of dengue is the most essential step to curb any mass outbreak of the disease.

\section{OBJECTIVES}

The objectives of the study were to find the existing knowledge of Dengue among medical professionals and preference of diagnostic techniques of dengue and to elicit acceptability and affordability of such measures and to highlight the policies regarding dengue diagnostics.

\section{METHOD}

A questionnaire survey was conducted among 100 doctors using a pretested open-ended questionnaire. The result was analysed and interpreted.

\section{RESULTS}

The knowledge of medical professionals regarding the preference of dengue diagnostics varies; $56 \%$ of the medical professionals prefer IgM antibody ELISA test, 41\% prefer NS I antigen test and only 3\% prefer RT - PCR; $100 \%$ of the medical professionals agreed that platelet count decreases during the course of infection. An increase of haematocrit value was thought to be important by $73 \%$ professionals. Interestingly, $20 \%$ of the medical professionals reported that no change in haematocrit value and $7 \%$ reported that haematocrit value would decrease. The knowledge of availability of ELISA was $72 \%$. However, $83 \%$ of medical professionals agreed that IgM antibody ELISA test was a rapid test for Dengue diagnosis.

\section{CONCLUSION}

Laboratory infrastructure, technical expertise and research capacity must be improved in order to positively influence dengue surveillance, clinical case management and development of new approaches to dengue control. CME on dengue is suggested to improve the knowledge on diagnostic facilities and its sensitivity, specificity and reliability.

\section{KEYWORDS}

Dengue, IgM Antibody, ELISA Test, NS I Antigen, Haematocrit Value, RT-PCR.

HOW TO CITE THIS ARTICLE: Kamaraj SS, Sankarlal RM, Mohamed I, et al. Knowledge of medical professionals towards dengue diagnostics. J. Evolution Med. Dent. Sci. 2016;5(44):2763-2766, DOI: 10.14260/jemds/2016/645

\section{INTRODUCTION}

Dengue is a mosquito-borne viral disease that produces variable symptoms ranging from asymptomatic infection to a life-threatening disease. Dengue Viruses (DENV 1-4) belong to the family Flaviviridae, genus Flavivirus. It is transmitted through bite of infected Aedes species principally through Aedes aegypti and Aedes albopictus. Approximately, 50 to 100 million infections occur each year leading to 5, 00,000 hospitalizations and 20,000 deaths globally as estimated by WHO. ${ }^{1}$

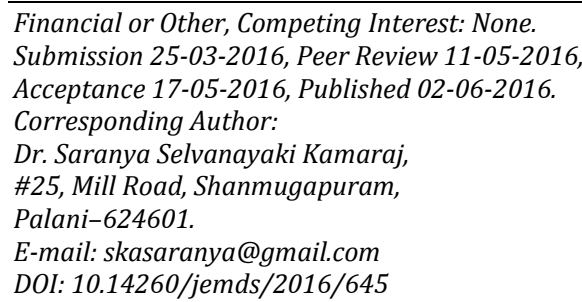

In many parts of the tropical and subtropical areas, dengue is endemic, that is it occurs every year, usually during a season when Aedes mosquito populations are high often when rainfall is optimal for breeding. Dengue infection manifests as Dengue Fever (DF), Dengue Haemorrhagic Fever (DHF), Dengue Shock Syndrome. High rate of morbidity and mortality occur due to Dengue infection throughout the world.

Appropriate intervention methods such as implementing early case detection, case management, adopting suitable vector control management, coordinated epidemic and entomological surveillance would help to predict the outbreak, which would enable early case detection and to implement preventive measures. Early diagnosis of Dengue has been considered as the most essential step to prevent any outbreak of the disease. In the first stage of infection, febrile condition with antigenemia, accompanied by appearance of NS1 antigen in blood, and during second stage a post febrile period in which IgM and IgG antibodies are in excess in the 
blood. In acute phase, dengue diagnosis is possible by detecting viral RNA/proteins in patient's blood. During the course of infection, platelet count will be below normal range $\left(1,50,000\right.$ to $4,50,000$ platelets $\left./ \mathrm{mm}^{3}\right)$, the haematocrit value will increase by about $20 \%$, which may vary with age and gender, and WBC count will be below normal range $(4,300-$ $10,800 \mathrm{WBCs} / \mathrm{mm}^{3}$ ), at this stage patient should be evaluated for dengue antigen test. ${ }^{2}$

Several laboratory methods such as Virus isolation, genomic RNA, antigen and antibody detection methods are available to diagnose Dengue infection. However, methods such as virus isolation and genomic RNA detection (PCR) need specialized, well equipped laboratory and trained personnel that can be established with high expenditure. ${ }^{3}$ Hence, the serological tests such as DENV antigens and DENV specific IgM and IgG by ELISA are practiced.

Hence, a person with either IgM positive in a single serum sample or IgG positive in a single serum sample with a Haemagglutination Inhibition (HI) titer of 1280 or greater is considered as suffering from Dengue infection. However, if a febrile person has one of the following, he/she is considered as a confirmed case of Dengue. ${ }^{4}$

- $\quad$ PCR positive.

- Virus culture positive.

- IgM seroconversion in paired sera.

- IgG seroconversion in paired sera or four-fold increase in IgG titer in paired sera.

Accurate diagnosis is essential for early initiation of specific preventive health measures. To date, accurate and timely diagnosis remains a problem for management of dengue infected patients in many parts of the world, especially in countries with limited resources.

This study was carried out to find out the knowledge and preference of available diagnostic techniques regarding dengue, to elicit acceptability and affordability regarding dengue diagnostics.

\section{MATERIALS AND METHODS}

A pretested open-ended questionnaire was designed and survey was conducted among 100 doctors. The survey was carried out in a tertiary care hospital, Tamilnadu. Anonymity of the participants was maintained throughout the study. The questionnaire contained 8 questions regarding dengue transmission, preference of diagnostic tests, haematological changes during infection and availability, affordability, sensitivity and rapidity of the tests. Information obtained was analysed using SPSS software V16.0.

\section{RESULTS}

All the 100 doctors responded and the response rate was $100 \%$ on all aspects. In this study, it was noted that $56 \%$ of medical professionals preferred for IgM antibody ELISA, 41\% preferred NS1 antigen detection and 3\% preferred RT-PCR (Figure 1).

Regarding the changes in WBC values, it was noted that $9 \%, 62 \%$ and $29 \%$ of the medical professionals considered that the count would be elevated, decreased and not changed respectively. All the 100 medical professionals agreed that there would be a decrease in platelet count; $73 \%$ were aware that the haematocrit values would increase; $7 \%$ replied that the haematocrit values would decrease and $20 \%$ reported that there would be no change in haematocrit values (Figure 2).

In this study, all the doctors participated (100\%) accepted that virus isolation and RT-PCR are available only in reference centres. It was observed that $24 \%$ of the participants reported that NS1 antigen ELISA is available in district centres only, $4 \%$ in reference centres only and $72 \%$ in both district and reference centres. Regarding IgM antibody ELISA, $24 \%, 4 \%$ and $72 \%$ of the doctors replied that it is available in district centres only, reference centres only and both district and reference centres respectively (Table 1).

As far as the affordability, sensitivity and rapidity of the diagnostics was concerned, $100 \%$ of medical professionals agreed that viral isolation and RT-PCR are not affordable. However, $55 \%$ of the doctors considered that RT-PCR was rapid considering the testing time was quick. Regarding NS1 antigen detection by ELISA, $72 \%$ agreed that was affordable, $89 \%$ reported that was sensitive and $73 \%$ had an opinion that was rapid; $7 \%$ of the participants agreed that IgM ELISA was affordable, 91\% reported that was sensitive and $83 \%$ had said it was rapid (Table 2).

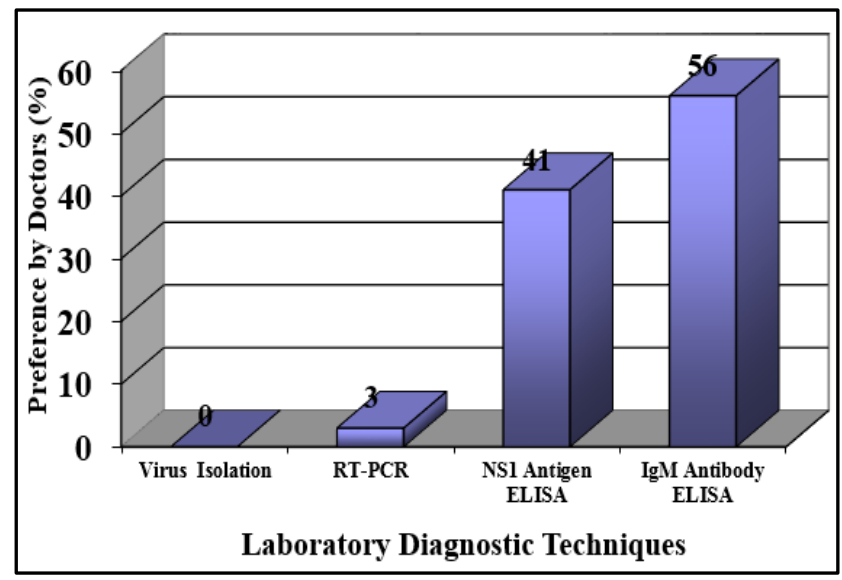

Fig. 1: Preference of Laboratory Diagnostics of Dengue (By Doctors)

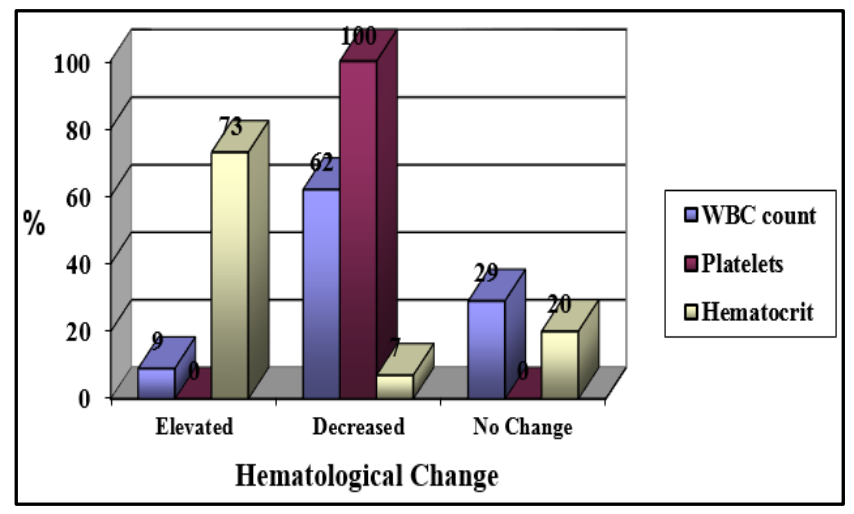

Fig. 2: Haematological Changes Expected by Doctors 


\begin{tabular}{|c|c|c|c|c|}
\hline \multirow{2}{*}{ Sl. No. } & \multirow{2}{*}{$\begin{array}{c}\text { Laboratory Diagnostic } \\
\text { Technique }\end{array}$} & $\begin{array}{c}\text { Availability of the Test } \\
\text { Centres Only }\end{array}$ & $\begin{array}{c}\text { In Reference } \\
\text { Centres Only }\end{array}$ & $\begin{array}{c}\text { In Both } \\
\text { Centres }\end{array}$ \\
\hline 1 & Virus Isolation & 0 & $100 \%$ & 0 \\
\hline 2 & RT-PCR & 0 & $100 \%$ & 0 \\
\hline 3 & NS1 Antigen ELISA & $24 \%$ & $4 \%$ & $72 \%$ \\
\hline 4 & IgM Antibody ELISA & $24 \%$ & $4 \%$ & $72 \%$ \\
\hline \multicolumn{4}{|r|}{} \\
\hline
\end{tabular}

\begin{tabular}{|c|c|c|c|c|}
\hline Sl. No. & Laboratory Diagnostic Technique & Affordable & Sensitive & Rapid \\
\hline 1 & Virus Isolation & 0 & $100 \%$ & 0 \\
\hline 2 & RT-PCR & 0 & $100 \%$ & $55 \%$ \\
\hline 3 & NS1 Antigen ELISA & $72 \%$ & $89 \%$ & $73 \%$ \\
\hline 4 & IgM Antibody ELISA & $79 \%$ & $91 \%$ & $83 \%$ \\
\hline \multicolumn{4}{|c|}{ Table 2: Awareness of Doctors on Affordability, Sensitivity and Rapidity of the Laboratory Diagnostics } \\
\hline
\end{tabular}

\section{DISCUSSION}

Accurate and timely diagnosis of the viral infection is essential for early intervention. Early diagnosis will be helpful for prognosis of severe forms of dengue, such as DHF/DSS and their prompt and appropriate treatment. Currently, dengue diagnosis is based on viral isolation, serology and RNA detection.

Virus isolation includes mosquito cell lines, mosquito inoculation techniques and vertebral cell cultures. ${ }^{2}$ Cell culture is the most widely used method for dengue virus isolation. ${ }^{4}$ Virus isolation followed by an immunofluorescence assay for confirmation generally requires 1-2 weeks. It is available only in Reference centres. ${ }^{4}$ Virus isolation technique is a sensitive and specific technique, but cumbersome to carry out considering the time needed and procedure to be followed. It is also expensive and carelessness in performing the test may cause infection to the technician. These are in accordance with the study of Azhar et al, ${ }^{5}$ who said that virus isolation technique is a gold standard technique, but is not used nowadays because of lower sensitivity compared to RT-PCR. Longer time (1-2 weeks) is needed for the isolation of the virus, which is possible only during the period of viremia (Usually 1-5 days). The viability of the virus depends on the handling of the samples. Virus isolation technique is to confirm the virus and type of virus such as Dengue 1, Dengue 2, Dengue 3 and Dengue 4. It is not a rapid test and will not be performed during epidemics.

Since 1990, nucleic acid detection (RT-PCR) is used in the diagnosis of viral infections. It is useful for early detection of dengue infection when antibodies are not detectable. RT-PCR has a sensitivity of about $80 \%-90 \%$ and specificity more than $95 \%{ }^{6}$ and it is possible to identify the serotypes and genotypes. ${ }^{4,7}$ It gives a faster result within 1-2 days as compared to virus isolation, provided all the required materials are available. It is available in Reference centres. ${ }^{4}$ It has a greater possibility to give false positive due to contamination and the need of expertise. ${ }^{7}$ The method does not help to differentiate between primary and secondary infections. It is expensive. In the study of Dutra et al, 8 it was described that the PCR techniques demand specific laboratory equipment and suitable infrastructure, in addition to an extensive evaluation protocol under the conditions of the field which the laboratory meets, since there may be differences between strains circulating in different places. According to Americas Dengue Prevention Board. ${ }^{9}$ Nucleic acid detection tests are very important, but are often not feasible because of their cost and complexity. This test is also not a rapid test and cannot be performed during epidemics routinely.

NS1 antigen detection shows a lower sensitivity than RTPCR, but can be used in laboratories that lack the facilities for expensive equipments. The sensitivity and specificity of NS1 antigen ELISA is $49 \%-59 \%$ and $93 \%-99 \%$ respectively. ${ }^{10}$ It is available in both district and reference centres. ${ }^{4}$ According to Bisordi et al,11 the NS1 assay is highly suitable for samples undergoing screening for virus isolation. Study of Andries et al,12 also revealed that the discovery of the NS1 protein as an early marker for DENV infection, especially in rapid diagnostic test format now allows dengue diagnosis during the early phase of the disease, even in laboratories with limited equipment and human resources. Shrivastava et al,13 study described that NS1 ELISA is a potentially useful test during early febrile stage. An outstanding point of the test is its high specificity during early infection. It also gives rapid results. However, cross-reaction are reported in NS1 ELISA.

IgM antibody detection is sensitive and easy and rapid to perform. The sensitivity and specificity of IgM ELISA is $90 \%$ and $98 \%$ respectively.6,14 It is being preferred for detection of dengue, but IgM detection requires appropriate collection time and its results may be confused with false-positive reactions (Since anti-DENV IgM shows extensive crossreaction) and by the prolonged presence of these antibodies in some people's blood. ${ }^{15}$ This test is feasible for suggesting a dengue infection and is also affordable by the patients, but needs two samples. It can also miss few cases, because IgM levels may be low in secondary infections. ${ }^{8}$

Recently, there has been a rapid growth of commercially available rapid detection tests. In general, the rapid detection tests are simple to perform and rapid to diagnose. These tests were used for quick screening and in laboratories that have limited resources, lack of viral culture or RT-PCR facilities.4,7 But their sensitivity is comparatively less than ELISA. ${ }^{16}$ The use of rapid tests for dengue diagnosis has been banned by the state government of Tamil Nadu, because of its high false positive results. ${ }^{17}$ According to health officials, the government has advised hospitals and laboratories not to conduct rapid card test for the time being as only ELISA test could confirm Dengue. Restriction of rapid tests is likely to bring down the number of cases and may reduce the opportunities for enforcing preventive measures. In the absence of availability of facilities to detect IgM by ELISA for 
Dengue, rapid tests may be used as alternative to suspect dengue infection.

Sekaran et al,18 described that virus isolation and RTPCR require specialized facilities and skill and are expensive. Hence, most laboratories use either in-house ELISAs or commercial kits to detect IgM and IgG antibodies.

This questionnaire study revealed that the knowledge and preference of medical professionals towards Dengue detection were not adequate. CME may be conducted to improve the knowledge on Dengue diagnostics for early detection and early intervention to prevent morbidity and mortality due to dengue infection.

\section{Limitation of the Study}

This is a single centred study. A multicentre study will reveal a real situation of existing knowledge of medical professional regarding Dengue diagnostics.

\section{ACKNOWLEDGEMENT}

We would like to thank the various Clinical Departments for their co-operation and co-ordination in the study.

\section{REFERENCES}

1. Idrees S, Ashfaq UA. A brief review on dengue molecular virology, diagnosis, treatment and prevalence in Pakistan. Genetic Vaccines and Therapy 2012;10:6.

2. Singhi S, Kissoon N, Bansal A. Dengue and dengue haemorrhagic fever: management issues in an intensive care unit. Journal de Paediatria 2007;83(2):22-35.

3. Kassim FM, Izati MN, TrRogayah TA, et al. Use of dengue NS1 antigen for early diagnosis of dengue virus infection. Southeast Asian J Trop Med Public Health 2011;42(3):562-9.

4. TDR/WHO dengue: guidelines for diagnosis, treatment, prevention and control (TDR/WHO, Geneva, Switzerland), 2009.

5. Azhar E, Kao M, Niedrig M, et al. Virological diagnosis of dengue fever in jeddah, Saudi Arabia: comparison between RT-PCR and virus isolation in cell culture. Journal of Infectious Diseases and Immunity 2012;2(2):24-9.

6. www.cdc.gov/dengue/clinicallab/laboratory.html.

7. Peeling RW, Artsob H, Pelegrino JL, et al. Evaluation of diagnostic tests: dengue. TDR/WHO Nature Reviews Microbiology 2010;S30-S37.
8. Dutra NR, de Paula MB, de Oliveira MD, et al. The laboratorial diagnosis of dengue: applications and implications. J Glob Infect Dis 2009;1(1):38-44.

9. America Dengue Prevention Board. Accelerating progress in dengue control: dengue diagnostics in the Americas. International Vaccine Institute, 2009.

10. Blacksell SD, Jarman RG, Bailey MS, et al. Evaluation of six commercial point-of-care tests for diagnosis of acute dengue infections: the need for combining NS1 antigen and IgM/IgG antibody detection to achieve acceptable levels of accuracy. Clinical and Vaccine Immunology 2011;18(12):2095-101.

11. Bisordi I, Rocco IM, Suzuki A, et al. Evaluation of dengue NS1 antigen detection for diagnosis in public health laboratories, Sao Paulo State, 2009. Rev Inst Med Trop Sao Paulo 2011;53(6):315-20.

12. Andries AC, Duong V, Ngan C, et al. Field evaluation and impact on clinical management of a rapid diagnostic kit that detects dengue NS1, IgM and IgG. PLoS Negl Trop Dis 2012;6(12):e1993.

13. Shrivastava A, Dash PK, Tripathi NK, et al. Evaluation of a commercial dengue NS1 enzyme-linked immunosorbent assay for early diagnosis of dengue infection. Indian J Med Microbiol 2011;29(1):51-5.

14. Buchy P, Yoksan S, Peeling RW, et al. Laboratory tests for the diagnosis of dengue virus infection. WHO scientific working group on dengue research, Geneva, Switzerland, 2006.

15. Hunsperger EA, Yoksan S, Buchy P, et al. Evaluation of commercially available anti-dengue virus immunoglobulin $\mathrm{M}$ tests. Emerg Infect Dis 2009;15(3):436-40.

16. Yusuf NW, Kausar N, Akbar R, et al. Comparison of diagnostic efficacy of rapid diagnostic devices for dengue virus infection-a pilot study. J Ayub Med Coll Abbottabad 2008;20(4):26-8.

17. http://www.thehindu.com/todays-paper/officials-seizedengue-rapid-card-test-kits/article4052968.ece.

18. Sekaran SD, Ew CL, Subramaniam G, et al. Sensitivity of dengue virus NS-1 detection and secondary infections. African Journal of Microbiology Research 2009;3(3):10510. 